\title{
Body mass index and mild cognitive impairment among rural older adults in China: the moderating roles of gender and age
}

Yemin Yuan ${ }^{1,2}$, Jie Li ${ }^{1}$, Nan Zhang ${ }^{3}$, Peipei Fu' ${ }^{1}$, Zhengyue Jing ${ }^{1}$, Caiting $\mathrm{Yu}^{1}$, Dan Zhao ${ }^{1}$, Wenting Hao ${ }^{1}$ and Chengchao Zhou ${ }^{1,4^{*}}$ (D)

\begin{abstract}
Background: Evidence concerning the association between body mass index (BMI) and cognitive function among older people is inconsistent. This study aimed to investigate gender and age as moderators in association between $\mathrm{BMI}$ and mild cognitive impairment (MCl) among rural older adults.

Methods: Data were derived from the 2019 Health Service for Rural Elderly Families Survey in Shandong, China. In total, 3242 people aged 60 years and above were included in the analysis. Multilevel mixed-effects logistic regression was used to examine the moderating roles of gender and age, then further to explore the relationship between $\mathrm{BMI}$ and $\mathrm{MCl}$.

Results: There were 601 (18.5\%) participants with MCI. Compared with normal BMI group, low BMI group had a higher risk of $\mathrm{MCl}$ among older people [adjusted odds ratio $(\mathrm{aOR})=2.08,95 \%$ confidence interval $(\mathrm{Cl}): 1.26-3.44$ ], women ( $\mathrm{aOR}=2.06,95 \% \mathrm{Cl}: 1.35-3.12)$, or the older elderly aged $\geq 75$ years old (aOR $=3.20,95 \% \mathrm{Cl}: 1.34-7.45)$. This effect remained statistically significant among older women $(\mathrm{aOR}=3.38,95 \% \mathrm{Cl}: 1.69-6.73)$. Among older men, elevated $\mathrm{BMl}$ group had a higher risk of $\mathrm{MCl}(\mathrm{aOR}=2.32,95 \% \mathrm{Cl}$ : 1.17-4.61) than normal BMl group.
\end{abstract}

Conclusions: Gender and age moderated the association between BMI and $\mathrm{MCl}$ among Chinese rural older adults. Older women with low BMI were more likely to have $\mathrm{MCl}$, but older men with elevated BMI were more likely to have $\mathrm{MCl}$. These findings suggest rural community managers strengthen the health management by grouping the weight of older people to prevent the risk of dementia.

Keywords: Body mass index, Mild cognitive impairment, Older adults, Gender difference, Age difference

\footnotetext{
* Correspondence: zhouchengchao@sdu.edu.cn

${ }^{1}$ Centre for Health Management and Policy Research, School of Public

Health, Cheeloo College of Medicine, Shandong University, Jinan 250012,

China

${ }^{4} \mathrm{NHC}$ Key Laboratory of Health Economics and Policy Research, Shandong University, 44 Wenhuaxi Road, Jinan 250012, Shandong, China

Full list of author information is available at the end of the article
}

(c) The Author(s). 2021 Open Access This article is licensed under a Creative Commons Attribution 4.0 International License, which permits use, sharing, adaptation, distribution and reproduction in any medium or format, as long as you give appropriate credit to the original author(s) and the source, provide a link to the Creative Commons licence, and indicate if changes were made. The images or other third party material in this article are included in the article's Creative Commons licence, unless indicated otherwise in a credit line to the material. If material is not included in the article's Creative Commons licence and your intended use is not permitted by statutory regulation or exceeds the permitted use, you will need to obtain permission directly from the copyright holder. To view a copy of this licence, visit http://creativecommons.org/licenses/by/4.0/ The Creative Commons Public Domain Dedication waiver (http://creativecommons.org/publicdomain/zero/1.0/) applies to the data made available in this article, unless otherwise stated in a credit line to the data. 


\section{Background}

Diseases related to cognitive impairment, especially dementia, are increasingly becoming prominent health threat and bring a huge burden in older people worldwide. In 2018, there were 50 million people with dementia around the world; this number will more than triple to 152 million by 2050 [1]. The worldwide cost of the disease was about US\$ 1 trillion in 2018, and that will rise to US\$ 2 trillion by 2030 [1]. The incidence of dementia in people aged 60 years old and over is 9.9 cases per 1000 person-years in China [2]. Based on estimation, the prevalence of dementia among individuals aged 65 years and older in China was around 5.1\% [3], and are increasing nationwide. Due to the limited treatments available for dementia at present, primary prevention is the best strategy to reduce the risk or delay the onset of dementia in late life [4]. Mild cognitive impairment $(\mathrm{MCI})$ is a key transitional state between normal aging and dementia [5]. Individuals with MCI have a higher risk of dementia, with a rate of $10-15 \%$ per year compared with the rate for healthy controls of $1-2 \%$ per year [6]. Therefore, identification of risk factors for MCI might be of significance to prevent dementia among older adults.

Body mass index (BMI) is considered one of the important factors affecting cognitive function. Previous studies found that unhealthy BMI was associated with cognitive function among older adults [7]. A crosssectional study from Malaysia concluded positive association between BMI and cognitive function, measured by Mini-Mental State Examination (MMSE) in older adults aged 60 years and above [8]. Another cohort study of older blacks and whites (aged 53-100) conducted in the United States indicated that late-life BMI was related to change in cognitive function, with lower BMI being related to faster rates of decline in summary measures of global cognition [9]. Some studies have found that elevated BMI was associated with lower structural integrity in a brain region connecting frontal and temporal lobes among older people, which might affect their cognitive function $[10,11]$. A retrospective cohort study found there was difference in associations between BMI, brain metabolism and connectivity in elderly females and males [12]. However, it is also not known whether there is a gender difference in the relationship between BMI and MCI.

A recent study indicated that higher BMI was associated with relatively poorer cognitive performance in older people aged 75 to 84 , while the opposite relationship was found in older people over 84 years old [13]. Another study found that obesity was associated with a lower risk of cognitive decline among older people age 65 or older was found, but this protective association did not exist in adults aged 45 to 65 [14]. However, a study examined increased BMI might adversely affect cognitive function in older people aged 65 and over, but not in younger cohort [15]. The reason for the inconsistent results in different age group between BMI and cognition might be that age plays a moderating role.

Currently, the moderating role of gender and age in the relationship between BMI and MCI among Chinese older people is unclear. The percentage of people in China aged 60 years or above is $16.7 \%$ (231 million people) in 2016, which is expected to be more than $33.3 \%$ (491 million) in 2050, being about double of the percentage in 2016 [16]. About three-quarters of China's elderly live in rural areas. Thus, the purpose of this study was to investigate the moderating effects of gender and age on the association between BMI and MCI among Chinese rural older adults.

\section{Methods}

\section{Study setting and participants}

This study used the data from the Health Service for Rural Elderly Families Survey in Shandong, which was conducted from May to June 2019 in Shandong province, China. There were more than 100 million people in Shandong in 2018, and people aged 60 and over accounted for $22.3 \%$ of the total population [17]. The population of Shandong also ranked the second among the total population of China [18], with largest number of elderly population. The multistage stratified cluster sampling method was used to select the subjects [19]. Firstly, according to the Gross Domestic Product (GDP) per capita in Shandong in 2018, we selected three rural counties (one above the medium level, Rushan from Weihai; one at the medium level, Qufu from Jining; and one below the medium level, Laoling from Dezhou) as study sites. Secondly, five townships were randomly selected from each rural county. Thirdly, we randomly selected four villages from each of the selected townships. Finally, older people aged or over 60 years old who were randomly selected from each sample village were recruited in the survey. Inclusion criteria were (1) permanent residents who lived in the village for over 6 months in the past year, and (2) aged 60 years old and above. Exclusion criterion were (1) respondents who had an inability to complete the interview or communicate with others, and (2) with a history of dementia by further asking the village doctors about the physical condition of the interviewees. All of the completed questionnaires were carefully checked by the supervisors after the interview each day. In total, 3600 individuals were recruited and 3243 completed the whole survey, with a response rate of $90.1 \%$. Of the 3243 respondents, one respondent was excluded from analysis due to the lack of data in cognitive survey. Finally, a total of 3242 rural older adults were included in the analysis. 


\section{Measures \\ Mild cognitive impairment}

Mild cognitive impairment (MCI) was measured by the 30-item Chinese version of the Mini-Mental State Examination (MMSE). The maximum score is 30 points, with the higher scores indicating a better cognitive function. It showed good reliability and validity as an instrument for detecting MCI among Chinese [20-22]. The widely accepted cut-off point to determine MCI in China (MMSE Chinese Standard, MCS) based on educationspecific are less than a score of 17 for respondents of illiteracy, less than a score of 20 for respondents of primary school, and less than a score of 24 for respondents of higher than primary school [23].

\section{Body mass index}

Body mass index (BMI) was calculated using the formula: BMI $\left(\mathrm{kg} / \mathrm{m}^{2}\right)=$ weight $(\mathrm{kg}) /$ height $^{2}\left(\mathrm{~m}^{2}\right)$. Height (in centimeter) was self-reported and weight (in kilogram) was measured by the interviewers. The self-reported height could underestimate overweight and obesity [24]. The same weight scale was used for all participants and the scale was calibrated before the measurement. BMI was categorized into underweight $\left(\mathrm{BMI}<18.5 \mathrm{~kg} / \mathrm{m}^{2}\right.$, low BMI), normal weight $\left(18.5 \mathrm{~kg} / \mathrm{m}^{2} \leq \mathrm{BMI}<24.0 \mathrm{~kg} / \mathrm{m}^{2}\right.$, normal BMI), overweight $\left(24.0 \mathrm{~kg} / \mathrm{m}^{2} \leq \mathrm{BMI}<28.0 \mathrm{~kg} / \mathrm{m}^{2}\right.$, elevated BMI), and obesity (BMI $\geq 28.0 \mathrm{~kg} / \mathrm{m}^{2}$, high BMI) according to the revised Asia-Pacific BMI criteria by the World Health Organization (WHO) [25].

\section{Covariates}

In this study, covariates included sociodemographic variables, health behavior and health status variables. Sociodemographic variables included age $(<75$ or $\geq 75$ years), gender (male or female), education (illiteracy, primary school, or junior high school or above), marital status (married or unmarried/widowed/divorced), and household income [quartile 1 (the poorest), quartile 2, quartile 3, or quartile 4 (richest)]. Health behavior variables included cigarette smoking (yes), alcohol consumption (yes), and physical activity (high level, moderate level, or low level). Health status variables included activities of daily livings (normal or impaired), mental health (good, general, worse, or bad), and chronic diseases (hypertension, diabetes, hyperlipidemia, coronary heart disease, and cerebrovascular disease). Participants reported whether they have been diagnosed with the above chronic conditions. Physical activity was measured by the Chinese version of the International Physical Activity Questionnaire Short Form (IPAQ-S) [26]. Activities of daily livings (ADL) were measured by the Instrumental Activity of Daily Living Scale (IADL). The score > 20 points indicates that there is a life activity disorder [27]. Level of mental health was measured by the Chinese version of the 10-item Kessler Psychological Distress Scale (K10). The total score ranges from 10 to 50 and can be divided into 4 groups: 10-15 indicating good mental health, 16-21 indicating general mental health, 22-29 indicating worse mental health, 30-50 indicating bad mental health [28].

\section{Statistical analysis}

We used Stata 16.0 to analyze the data. Firstly, descriptive statistics were used to describe baseline characteristics of participants with frequency (percentage). Pearson's chisquare test for categorical variables was used to compare different groups without or with MCI. Then, since 3242 participants came from 60 villages and 2928 families, multilevel mixed-effects logistic regression was used to examine the moderating role of gender and age. Associations between BMI and MCI were also assessed by multilevel mixed-effects logistic regression. More details about multilevel mixed-effects logistic regression were described in Additional file 1. The odds ratio (OR) and 95\% confidence interval (CI) were presented as measures of effect. In model 1, none covariates were included. In the literature [7, 29], we found that age, gender, education and other confounding factors may also affect the cognition of old people. Therefore, model 2 was based on model 1 , with additional adjusting for the statistically significant $(p$ value $<0.05)$ covariates of the previous single factor analysis. We also used Firth method as a sensitivity analysis in Additional file 2 . The statistically significant threshold was set at a two-sided and $p$-value $<0.05$.

\section{Results}

\section{Characteristics}

Baseline characteristics of participants are shown in Table 1. Of 3242 participants, the prevalence of MCI defined by MMSE was $18.5 \%$. The average age was $70.14 \pm$ 6.17 years (range 60-100). About two-thirds of the participants were female. At baseline, 165 (5.1\%) participants were low BMI. Among the participants with MCI, the mean BMI was $23.3 \mathrm{~kg} / \mathrm{m}^{2}$ (SD: 3.9), while the mean BMI was $24.5 \mathrm{~kg} / \mathrm{m}^{2}$ (SD: 3.9) in participants without MCI. There are some surprising findings here: the participants with $\mathrm{MCI}$ tended to be younger, female group, have not gone to school, with moderate physical exercise, without activity disorder, with good mental health. From Table 1, it doesn't seem like there is a higher proportion of young people in the MCI group, but rather a higher proportion of old persons. The distribution of MMSE scores in the participants is presented in Additional file 3.

\section{Moderating effects of gender and age on the association between $\mathrm{BMI}$ and $\mathrm{MCl}$}

Figure 1 shows the interaction between BMI, gender and age in the prediction of cognitive function with unadjusted 
Table 1 Baseline characteristics according to cognitive function

\begin{tabular}{|c|c|c|c|c|}
\hline \multirow[t]{2}{*}{ Characteristics } & \multirow[t]{2}{*}{ N (\%) } & \multicolumn{2}{|c|}{ Mild cognitive impairment } & \multirow[t]{2}{*}{$p$-valve } \\
\hline & & No (\%) & Yes (\%) & \\
\hline Total & $3242(100.00)$ & $2641(81.46)$ & $601(18.54)$ & \\
\hline Age & & & & $<0.001$ \\
\hline$<75$ & $2499(77.08)$ & $2127(80.54)$ & $372(61.90)$ & \\
\hline$\geq 75$ & $743(22.92)$ & $514(19.46)$ & $229(38.10)$ & \\
\hline Gender & & & & $<0.001$ \\
\hline Male & $1181(36.43)$ & $1009(38.21)$ & $172(28.62)$ & \\
\hline Female & $2061(63.57)$ & $1632(61.79)$ & 429 (71.38) & \\
\hline Education & & & & $<0.001$ \\
\hline Illiteracy & $1353(41.73)$ & $1005(38.05)$ & $384(58.90)$ & \\
\hline Primary school & $1257(38.77)$ & $1107(41.92)$ & $150(26.96)$ & \\
\hline Junior high school or above & $632(19.49)$ & $529(20.03)$ & $103(17.14)$ & \\
\hline Marital status & & & & $<0.001$ \\
\hline Married & $2415(74.49)$ & $2065(78.19)$ & $350(58.24)$ & \\
\hline Unmarried/widowed/divorced & $827(25.51)$ & $576(21.81)$ & $251(41.76)$ & \\
\hline Household income & & & & $<0.001$ \\
\hline Quartile 1 (the poorest) & $816(25.17)$ & $589(22.30)$ & $227(37.77)$ & \\
\hline Quartile 2 & $803(24.77)$ & $660(24.99)$ & $143(23.79)$ & \\
\hline Quartile 3 & $809(24.95)$ & $692(26.20)$ & $117(19.47)$ & \\
\hline Quartile 4 (the richest) & $814(25.11)$ & $700(26.51)$ & $114(18.97)$ & \\
\hline Cigarette smoking, yes & $1003(30.94)$ & $846(32.03)$ & $157(26.12)$ & 0.005 \\
\hline Alcohol consumption, yes & $922(28.44)$ & $782(29.61)$ & $140(23.29)$ & 0.002 \\
\hline Physical activity & & & & $<0.001$ \\
\hline High level & $1322(40.78)$ & $1169(44.26)$ & $153(25.46)$ & \\
\hline Moderate level & $1358(41.89)$ & $1074(40.67)$ & $284(47.25)$ & \\
\hline Low level & $562(17.33)$ & $398(15.07)$ & $164(27.29)$ & \\
\hline $\mathrm{ADL}$ & & & & $<0.001$ \\
\hline Normal & $2849(87.88)$ & $2383(90.23)$ & $466(77.54)$ & \\
\hline Impaired & $393(12.12)$ & $258(9.77)$ & $135(22.46)$ & \\
\hline Mental health & & & & $<0.001$ \\
\hline Good & $1845(56.91)$ & $1557(58.95)$ & $288(47.92)$ & \\
\hline General & $637(19.65)$ & $516(19.54)$ & $121(20.13)$ & \\
\hline Worse & $515(15.89)$ & $391(14.80)$ & $124(20.63)$ & \\
\hline Bad & $245(7.55)$ & $177(6.71)$ & $68(11.32)$ & \\
\hline Hypertension, yes & $1478(45.59)$ & $1206(45.66)$ & $272(45.26)$ & 0.857 \\
\hline Diabetes, yes & $389(12.00)$ & $331(12.53)$ & $58(9.65)$ & 0.050 \\
\hline Hyperlipidemia, yes & $146(4.50)$ & $123(4.66)$ & $23(3.83)$ & 0.376 \\
\hline Coronary heart disease, yes & $572(17.64)$ & $468(17.72)$ & $104(17.30)$ & 0.809 \\
\hline Cerebrovascular disease, yes & $202(6.23)$ & $160(6.06)$ & $42(6.99)$ & 0.395 \\
\hline $\mathrm{BMI}$ & $24.31(3.92)$ & $24.54(3.89)$ & $23.29(3.86)$ & $<0.001$ \\
\hline Low BMl & $165(5.09)$ & $105(3.98)$ & $60(9.98)$ & \\
\hline Normal BMI & $1397(43.09)$ & $1107(41.92)$ & $290(48.25)$ & \\
\hline Elevated BMI & $1160(35.78)$ & $972(36.80)$ & $188(31.28)$ & \\
\hline High BMI & $520(16.04)$ & $457(17.30)$ & $63(10.49)$ & \\
\hline
\end{tabular}


Table 1 Baseline characteristics according to cognitive function (Continued)

\begin{tabular}{llll}
\hline Characteristics & N (\%) & \multicolumn{2}{l}{ Mild cognitive impairment } \\
\cline { 3 - 4 } & & No (\%) & Yes (\%) \\
\hline MMSE scores, Mean (SD) & $22.91(5.11)$ & $24.63(3.54)$ & $15.35(3.90)$ \\
$2-17$ & $406(12.52)$ & - & $406(67.55)$ \\
$18-20$ & $372(11.47)$ & $251(9.50)$ & $121(20.13)$ \\
$21-24$ & $759(23.41)$ & $685(25.94)$ & $74(12.31)$ \\
$25-30$ & $1705(52.59)$ & $1705(64.56)$ & - \\
\hline
\end{tabular}

$A D L$ activities of daily livings, $B M I$ body mass index, MMSE Mini-Mental State Examination, $S D$ standard deviation

95\% CI based on the model 1 . There were significant interactions in $\mathrm{BMI} \times$ gender, $\mathrm{BMI} \times$ age with $\mathrm{MCI}$ in low BMI and women group, as well as elevated BMI and older elderly group. When exploring joint interactions of BMI $\times$ gender and $\mathrm{BMI} \times$ age with $\mathrm{MCI}$ was statistically significant in elevated BMI and older elderly group, as well as low BMI, women and older elderly group. Figure 2 shows the interaction between BMI, gender and age in the prediction of cognitive function with adjusted 95\% CI based on the model 2. After adjusted for covariates, the interactions of each group were still statistically significant.

\section{Association between $\mathrm{BMI}$ and $\mathrm{MCl}$ in older adults and subgroups}

Table 2 presents the relationship between BMI and MCI among older people and subgroups. Among whole participants, low BMI was associated with a higher risk of MCI $(\mathrm{aOR}=2.08,95 \% \mathrm{CI}: 1.26-3.44, p<0.01)$, and high
BMI was correlated with a lower risk of MCI $(\mathrm{aOR}=$ 0.55, 95\% CI: $0.37-0.82, p<0.01)$ when compared to normal BMI. Low BMI was also associated with a higher risk of $\mathrm{MCI}(\mathrm{aOR}=2.06,95 \% \mathrm{CI}: 1.35-3.12, p<0.01)$, and high BMI was correlated with a lower risk of $\mathrm{MCI}$ $(\mathrm{aOR}=0.52,95 \%$ CI: $0.36-0.75, p<0.01)$ only in women. In the younger elderly $(<75$ years old $)$, participants with elevated BMI $(\mathrm{aOR}=0.66,95 \%$ CI: $0.47-0.93, p<0.05)$ and high $\mathrm{BMI}(\mathrm{aOR}=0.53,95 \% \mathrm{CI}: 0.33-0.84, p<0.01)$ were less likely to have $\mathrm{MCI}$. On the contrary, participants with low BMI had higher odds of MCI $(\mathrm{aOR}=$ 3.20 , 95\% CI: $1.34-7.45, p<0.01)$ in the older elderly ( $\geq 75$ years old).

\section{Association between $\mathrm{BMI}$ and $\mathrm{MCl}$ in four subgroups by gender and age}

Results of association between BMI and MCI in four subgroups divided by gender and age are shown in
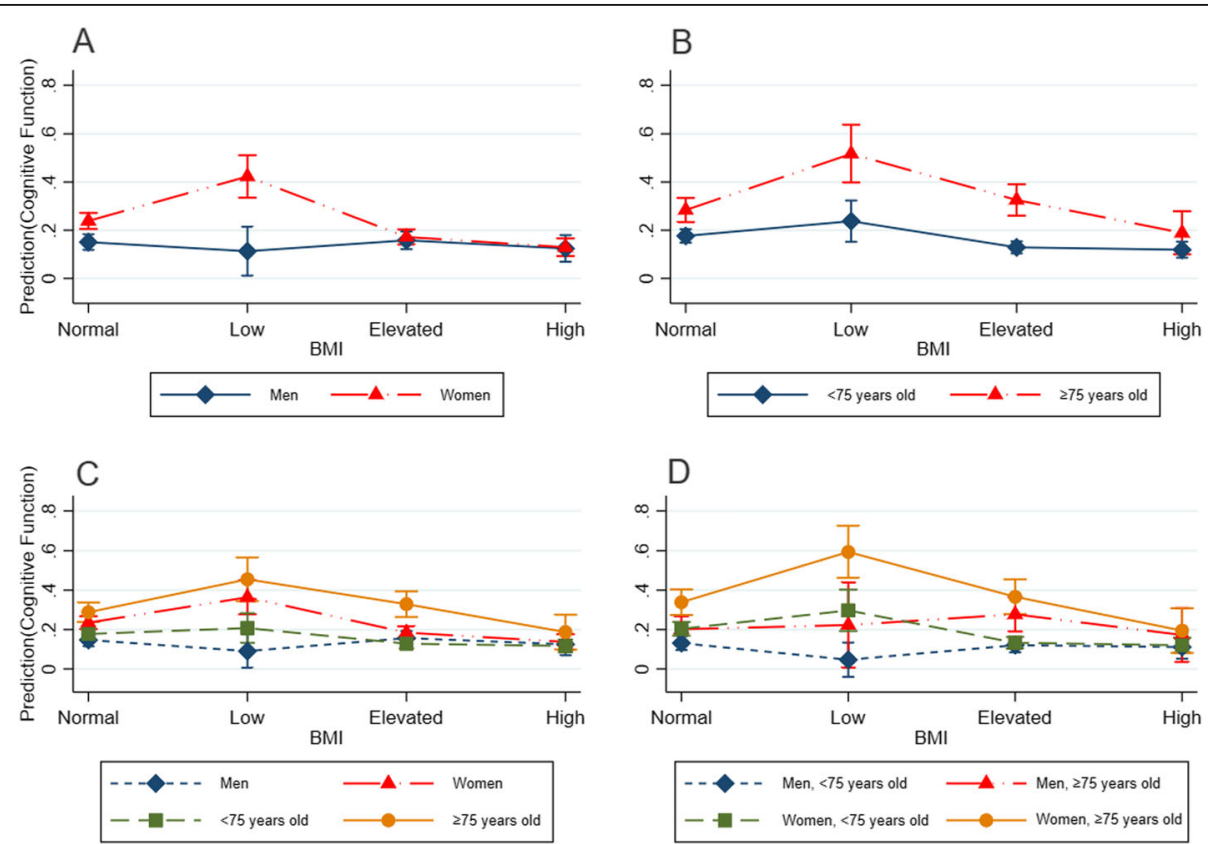

Fig. 1 Interaction between BMl, gender and age in the prediction of cognitive function with unadjusted 95\% confidence interval based on the model 1. BMI, body mass index. a represents $\mathrm{BMI} \times$ gender. $\mathbf{b}$ represents $\mathrm{BMI} \times$ age. $\mathbf{c}$ represents $\mathrm{BMI} \times$ gender and $\mathrm{BMI} \times$ age. $\mathbf{d}$ represents $\mathrm{BMI} \times$ gender $\times$ age 

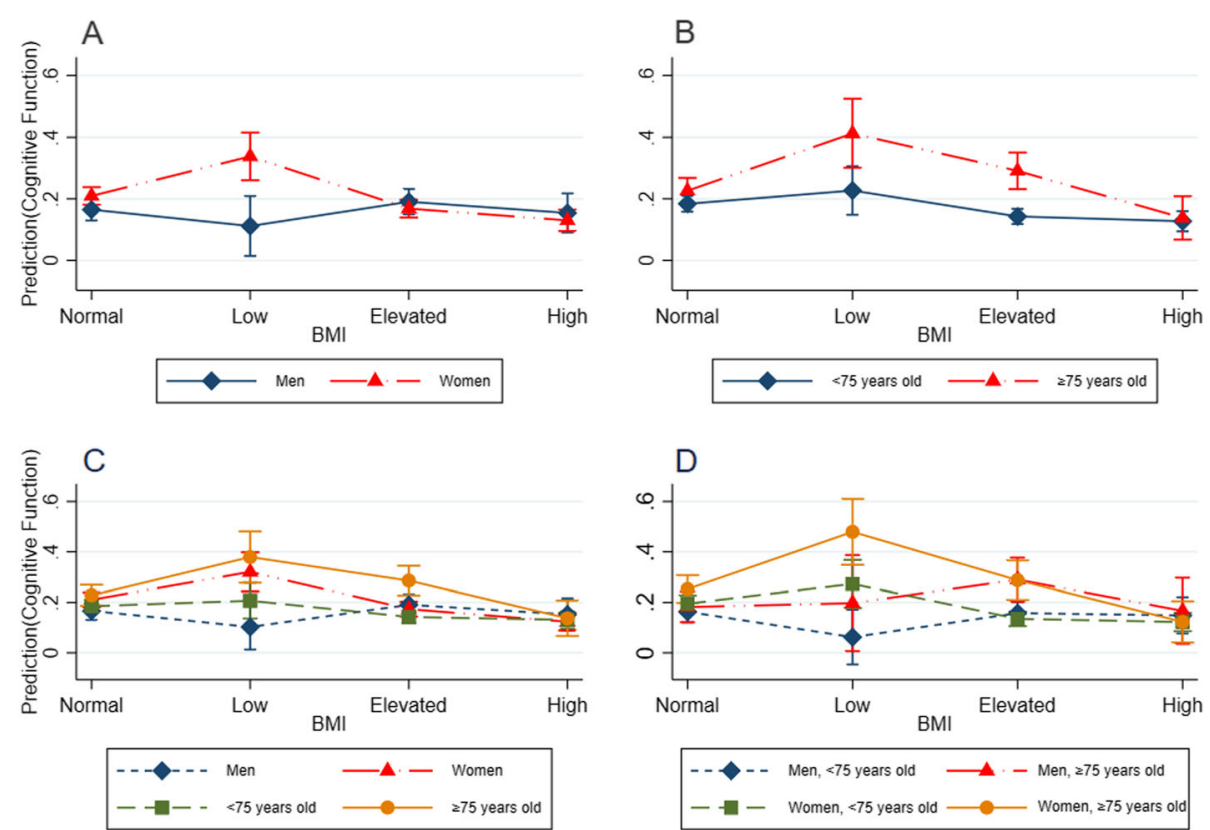

Fig. 2 Interaction between BMI, gender and age in the prediction of cognitive function with adjusted 95\% confidence interval based on the model 2. BMI, body mass index. Model 2 was adjusted for age, gender, marital status, household income, cigarette, alcohol consumption, physical activity, activities of daily livings, mental health. a represents $\mathrm{BMI} \times$ gender. $\mathbf{b}$ represents $\mathrm{BMI} \times$ age. $\mathbf{c}$ represents $\mathrm{BMI} \times$ gender and $\mathrm{BMI} \times$ age. $\mathbf{d}$ represents $\mathrm{BMI} \times$ genderxage

Table 3. Comparing to normal BMI, elevated BMI was correlated with a higher risk of $\mathrm{MCI}(\mathrm{aOR}=2.32,95 \%$ CI: $1.17-4.61, p<0.05)$ among older men. Among younger women, elevated BMI $(\mathrm{aOR}=0.60$, 95\% CI: 0.44$0.83, p<0.01)$ and high BMI $(\mathrm{aOR}=0.52$, 95\% CI: $0.35-$ $0.79, p<0.01)$ were associated with a lower risk of MCI. Among the older women, low BMI was associated with a higher risk of $\mathrm{MCI}(\mathrm{aOR}=3.38,95 \% \mathrm{CI}: 1.69-6.73, p<$ $0.01)$. High BMI remained related to a lower risk of MCI $(\mathrm{aOR}=0.39,95 \% \mathrm{CI}: 0.16-0.93, p<0.05)$ among older women. An analysis of a non-linear association between BMI and MMSE score with stratification on gender and age is shown in Additional file 4.

\section{Discussion}

In this study, we found the prevalence of $\mathrm{MCI}$ among rural older people was $18.5 \%$. The prevalence in present study was higher than older adults $(60+)$ in Shanghai suburb (by MMSE, 7.0\%) [30], and older people (65+) from 8 longevity areas of China (by MMSE, 10.0\%) [31]. A survey of community-based cohort in Zhejiang Province showed that the prevalence of MCI (by MMSE) among older adults (60+) was $14.7 \%$ [7]. The prevalence of MCI among older people in previous studies was lower than that in present study. This may be because that we only focused on the older adults in rural areas, and previous studies have indicated that the prevalence of MCI in rural areas was significantly higher than that in urban areas [32].

The moderating effect of gender between BMI and MCI was found. Similar to previous studies, older women with low BMI were more likely to have MCI and those with elevated or high BMI were less likely to have MCI. However, the relationships were not significant in males. Malnutrition could be a risk factor for cognitive decline among older people [33]. BMI is an important objective indicator assessing the nutritional status among older people. Low BMI might be related to malnutrition. One possible explanation for the observed gender difference might be that differences in estrogen levels. Estrogen is a group of steroid compounds that function as primary gender hormones in women [34]. Estrogen interacts with different types of receptors to exerted its action, including estrogen receptors ER- $\alpha$ and ER- $\beta$ that are highly expressed in the brain [35]. In men, testosterone is converted to estradiol by aromatase enzyme, which is located around and throughout the male brain [36]. Since the secretion of testosterone has never completely stopped, the serum estrogen levels are higher among older men than in postmenopausal older women. Studies have shown that sex steroids such as estrogen and testosterone could protect the brain's function during aging [37]. Thus, different levels of steroids in men and women may affect their cognitive function to varying degrees. 


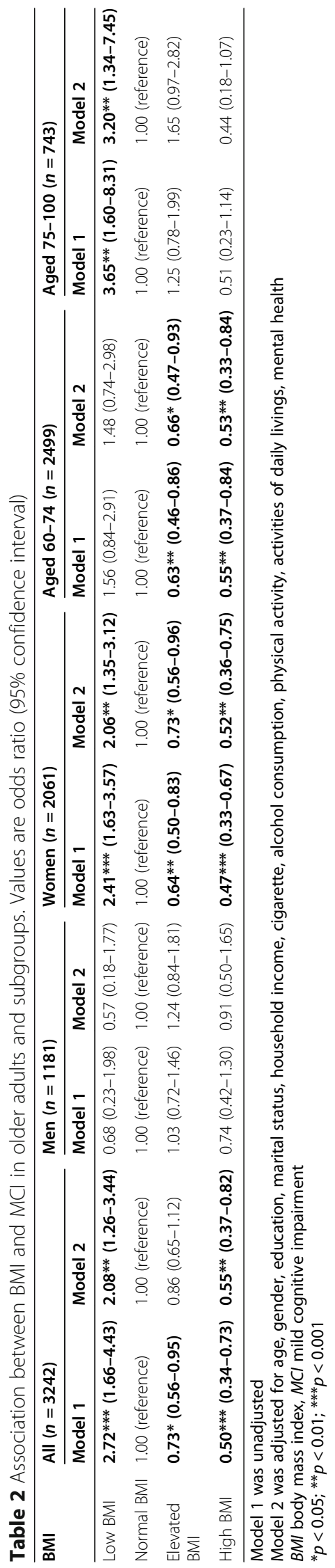




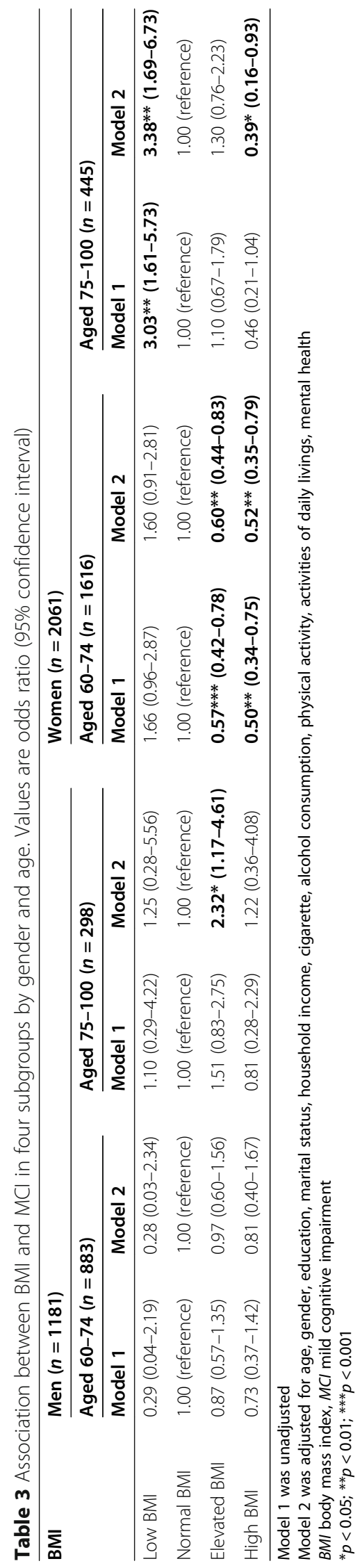


The moderating effect of age between BMI and MCI was found. Different from previous studies, low BMI was positively correlated with $\mathrm{MCI}$ in older elderly, and elevated or high $\mathrm{BMI}$ was negative correlated with $\mathrm{MCI}$ in younger elderly. Respecting the differences between younger and older elderly, a possible explanation was that older elderly became more frail as they got older and the frailty accelerated increases. Frailty in older people were predisposed to a homeostatic failure of complex systems [38], which could lead to more functional deficits. In Chinese rural areas, the degree of frailty of older people remained at a high level, and more than half of elderly households were moderate and advanced frailty [39]. Studies have found that the prevalence of cognitive impairment in the frail elderly was higher than that of non-frail elderly [40, 41]. Another possible reason was that the overall BMI decreased with age among older people. Lower BMI might affect brain atrophy through changes in metabolic and inflammatory [42]. Another important reason might be related to alterations in body composition. Aging was characterized by the decrease of lean body mass, and higher lean body mass might reduce the risk of cognitive impairment among older people [43], which could contribute to a lower risk of development of MCI in younger elderly with elevated or high BMI.

Inconsistent with previous studies, we found elevated BMI was positively correlated with $\mathrm{MCI}$ in older male elderly. Previous studies from South Korea [14, 44], Australia [45], and the United States [13] have found that higher BMI was not associated with decreased cognitive function or with better cognitive performance among older men. Amyloid-beta protein produced by amyloid precursor protein (app) cleavage could form amyloid aggregates and has long been considered the culprit for Alzheimer's [46]. A recent study found that dysregulation of app impairs adipose tissue mitochondrial function and promotes obesity [47]. Therefore, the association between elevated BMI and MCI in older male elderly might be due to the common pathological mechanism: abnormal amyloid precursor protein. However, the gender and age differences need to be further studied.

Moreover, we further found this association between low BMI and MCI became stronger among older women. It had been shown previously that older adults who had low BMI or lost weight were predisposed to cognitive decline. Previous studies from China [30, 31], South Korea [44], and the United States [48] differing from the results of this study have found only that underweight was associated with MCI in women or older adults in general. We should pay more attention to the relationship between low BMI and cognitive function among older women.
The findings demonstrated the importance of managing the weight of rural older adults by gender and age. Government departments should strengthen the health management of malnutrition or low BMI for the rural older people, especially in the older female elderly. We recommend strengthening the information management of BMI and cognitive function among rural older adults. We suggest combine the basic public health services for the health management among older people to improve their understanding of the healthy weight. By grouping the weight of older people, high-risk groups with impaired cognitive function can be detected early to prevent the risk of dementia and maintain the well-being of older adults.

The current study had several limitations. First, waist circumference was not included to assess elevated or high BMI among older people; we will include this indicator in the following study. We would use a portable stadiometer to measure height objectively for the future research. Second, we could not determine the causal relationship between BMI and MCI as the cross-sectional data we used, longitudinal studies are needed in the future to explore the causal relationships.

\section{Conclusions}

This study demonstrated that the relationship between $\mathrm{BMI}$ and MCI was moderated by gender and age. Older adults, especially older women with a low BMI, had a higher risk of $\mathrm{MCI}$, compared to the normal BMI. Older men with elevated BMI more likely to have MCI. Government departments should strengthen the health management of rural elderly with malnutrition or low BMI, especially older women.

\section{Supplementary Information}

The online version contains supplementary material available at https://doi. org/10.1186/s12888-021-03059-8.

Additional file 1. An introduction of multilevel mixed-effects logistic regression

Additional file 2. A sensitivity analysis

Additional file 3: Figure S1. Distribution of MMSE scores among older adults

Additional file 4. An analysis of a non-linear association

\section{Abbreviations}

BMI: Body mass index; MCl: Mild cognitive impairment; MMSE: Mini-Mental State Examination

\section{Acknowledgments}

We are grateful to all participants for their effort. We thank the officials of local health agencies and staffs at the study sites for their cooperation.

\section{Authors' contributions}

CZ designed the study, supervised the data collection, and revised the manuscript. YY performed all statistical analyses and drafted the manuscript. $J \mathrm{~L}$ and $\mathrm{NZ}$ gave many valuable comments on the draft and also polished it. PF and ZJ helped to plan the study, including the investigation. CY, DZ and 
WH participated in data collection and statistical analysis. All authors read and approved the final manuscript.

\section{Funding}

This work was supported by the National Natural Science Foundation of China [grant numbers 71774104, 71473152, 71974117]; the China Medical Board [grant number 16--257]; Cheeloo Youth Scholar Grant; and Shandong University [grant numbers IFYT1810, 2012DX006]. The funding organizations had no role in the design of the study and collection, analysis and interpretation of data and in writing the manuscript.

\section{Availability of data and materials}

Our data may not be shared directly, because it is our teamwork; informed consent should be attained from all the team members. The datasets used and/or analysed during the current study are available from the corresponding author on reasonable request.

\section{Ethics approval and consent to participate}

The protocol for this study was approved by the Ethical Committee of School of Public Health, Shandong University (approval number, 20181228). The investigation was conducted after the acquisition of written informed consent of all participants. The data used in this study was anonymised before its use.

\section{Consent for publication}

Not applicable.

\section{Competing interests}

The authors declare that they have no competing interests.

\section{Author details}

${ }^{1}$ Centre for Health Management and Policy Research, School of Public Health, Cheeloo College of Medicine, Shandong University, Jinan 250012, China. ${ }^{2}$ Department of Epidemiology, School of Public Health, Cheeloo College of Medicine, Shandong University, 44 Wenhuaxi Road, Jinan 250012, Shandong, China. ${ }^{3}$ Manchester Institute for Collaborative Research on Ageing, Social Statistics, School of Social Sciences, The University of Manchester, Manchester, UK. ${ }^{4} \mathrm{NHC}$ Key Laboratory of Health Economics and Policy Research, Shandong University, 44 Wenhuaxi Road, Jinan 250012, Shandong, China.

Received: 16 September 2020 Accepted: 17 January 2021 Published online: 23 January 2021

\section{References}

1. Alzheimer's Disease International. World Alzheimer Report. The state of the art of dementia research: New frontiers. London: Alzheimer's Disease International; 2018. p. 6-7.

2. Chan KY, Wang W, Wu J, Liu L, Theodoratou E, Car J, et al. Epidemiology of Alzheimer's disease and other forms of dementia in China, 1990-2010: a systematic review and analysis. Lancet. 2013;381(9882):2016-23.

3. Jia J, Wang F, Wei C, Zhou A, Jia X, Li F, et al. The prevalence of dementia in urban and rural areas of China. Alzheimers Dement. 2014;10(1):1-9.

4. Imtiaz B, Tolppanen A-M, Kivipelto M, Soininen $\mathrm{H}$. Future directions in Alzheimer's disease from risk factors to prevention. Biochem Pharmacol. 2014:88(4):661-70

5. Petersen RC, Smith GE, Waring SC, Ivnik RJ, Tangalos EG, Kokmen E. Mild cognitive impairment: clinical characterization and outcome. Arch Neurol. 1999:56(3):303-8.

6. Xu S, Xie B, Song M, Yu L, Wang L, An C, et al. High prevalence of mild cognitive impairment in the elderly: A community-based study in four cities of the Hebei province, China. Neuroepidemiology. 2014;42(2):123-30.

7. Zhang T, Yan R, Chen Q, Ying X, Zhai Y, Li F, et al. Body mass index, waistto-hip ratio and cognitive function among Chinese elderly: a cross-sectional study. BMJ Open. 2018;8(10):e022055

8. Wang F, Zhao M, Han Z, Li D, Lei P. Association of body mass index with amnestic and non-amnestic mild cognitive impairment risk in elderly. BMC Psychiatry. 2017;17(1):334

9. Zoe A, Capuano AW, Bennett DA, Barnes LL. Body mass index and decline in cognitive function in older black and white persons. J Gerontol Med Sci. 2017;78(2):198-203.
10. Bolzenius JD, Laidlaw DH, Cabeen RP, Conturo TE, Mcmichael AR, Lane EM, et al. Brain structure and cognitive correlates of body mass index in healthy older adults. Behav Brain Res. 2015;278:342-7.

11. Gogniat MA, Robinson TL, Mewborn CM, Jean KR, Miller LS. Body mass index and its relation to neuropsychological functioning and brain volume in healthy older adults. Behav Brain Res. 2018;348:235-40.

12. Sala A, Malpetti M, Ferrulli A, Gianolli L, Luzi L, Perani D. High body mass index, brain metabolism and connectivity an unfavorable effect in elderly females. Aging-US. 2019;11(19):8573-86.

13. Schmeidler J, Mastrogiacomo CN, Beeri MS, Rosendorff C, Silverman JM. Distinct age-related associations for body mass index and cognition in cognitively healthy very old veterans. Int Psychogeriatr. 2019;31(6):895-9.

14. Kim S, Kim Y, Park SM. Body mass index and decline of cognitive function. PLoS One. 2016;11(2):e0148908.

15. Lojlo D, Palys W, Czajkowska A, Wieczorowska-Tobis K, LUKASIK S, Gorna K, et al. Association of cognitive performance with the physical activity and body mass index in middle-aged and older rural inhabitants. Eur Rev Med Pharmacol Sci. 2014;18(23):3645-52.

16. Hu J. China's population aging status, trends and suggestions. China Econ Trade Herald. 2017:4:59-62.

17. Statistics Bureau of Shandong Province. Shandong Statistical Yearbook 2019 Beijing: China Statistics Press; 2019.

18. National Bureau of Statistics. China Statistical Yearbook 2019. Beijing: China Statistics Press; 2019

19. Jing $Z$, Li J, Wang $Y$, Ding $L$, Tang $X$, Feng $Y$, et al. The mediating effect of psychological distress on cognitive function and physical frailty among the elderly: Evidence from rural Shandong, China. J Affect Disord. 2020;268:88-94.

20. Wang Z, Zhang M, Zhai G, Chen J, Zhao J. Application of Chinese version of mini-mental state examination (MMSE). Shanghai Arch Psychiatry. 1989;7(3): 108-11.

21. Wang $Y$. The rating scales for neurology. Beijing: China Friendship Publishing Company; 2005

22. Liu M, He $Y$, Jing $B$, Wu L, Wang J, Yang $S$, et al. Association between metabolic syndrome and mild cognitive impairment and its age difference in a chinese community elderly population. Clin Endocrinol. 2015;82(6):844-53

23. Wu L, He Y, Jiang B, Liu M, Wang J, Yang S, et al. The association between the prevalence, treatment and control of hypertension and the risk of mild cognitive impairment in an elderly urban population in China. Hypertens Res. 2016;39(5):367-75.

24. Kuczmarski MF, Kuczmarski R, Najjar R. Effects of age on validity of selfreported height, weight, and body mass index findings from the third National Health and nutrition examination survey, 1988-1994. J Am Diet Assoc. 2001;101(1):28-34

25. Zhou B. Predictive values of body mass index and waist circumference for risk factors of certain related diseases in Chinese adults: study on optimal cut-off points of body mass index and waist circumference in Chinese adults. Biomed Environ Sci. 2002:15(1):83-96.

26. Tao $Y$, Wang $L$, Dong $X$, Zheng H, Zheng $Y$, Tang $X$, et al. Psychometric properties of the physical activity scale for the elderly in Chinese patients with COPD. Int J COPD. 2016;12:105-14.

27. Zheng J, Chen X. Influence of depression and activities of daily living on cognitive function of community elderly people. Chin Nurs Res. 2017;31(3): 285-8.

28. Ma J, Li S, Zhang Y. Survey on the mental health status of white collars based on scale of Kessler 10. Pract Prev Med. 2014;21(1):25-7.

29. Rodríguez-Fernández JM, Danies E, Martínez-Ortega J, Chen WC. Cognitive decline, body mass index, and waist circumference in community-dwelling elderly participants: results from a nationally representative sample. J Geriatr Psychiatry Neurol. 2017;30(2):67-76.

30. Cui G, Guo H, Xu R, Jiang G, Chen S, Qi C. The association of weight status with cognitive impairment in the elderly population of a Shanghai suburb. Asia Pac J Clin Nutr. 2013;22(1):74-82.

31. Zhang J, LV Y, Yin Z, Luo J, Shi W, Shi X. Follow-up study of body mass index and risk of cognitive impairment among elderly adults aged $\geq 65$ years old from longevity areas of China. Chin J Prev Med. 2017:51(11):1019-23.

32. Nie H, Xu Y, Liu B, Zhang Y. The prevalence of mild cognitive impairment about elderly population in China: a meta-analysis. Int J Geriatr Psychiatry. 2011;26(6):558-63. 
33. Khater MS, Abouelezz NF. Nutritional status in older adults with mild cognitive impairment living in elderly homes in Cairo, Egypt. J Nutr Health Aging. 2011;15(2):104-8.

34. Inestrosa NC, Marzolo M, Bonnefont AB. Cellular and molecular basis of estrogen's neuroprotection. Mol Neurobiol. 1998;17(1-3):73-86.

35. Mosselman S, Polman J, Dijkema R. ERB: identification and characterization of a novel human estrogen receptor. FEBS Lett. 1996;392(1):49-53.

36. Miranda RC, Toran-Allerand CD. Developmental expression of estrogen receptor mRNA in the rat cerebral cortex: a nonisotopic in situ hybridization histochemistry study. Cereb Cortex. 1992;2(1):1-15.

37. Hogervorst $E$, Jager $C D$, Budge $M$, Smith AD. Serum levels of estradiol and testosterone and performance in different cognitive domains in healthy elderly men and women. Psychoneuroendocrinology. 2004;29:404-21.

38. Lenore D, Mieke D, Sabine V, Jos T, Evelien G. Effects of multi-domain interventions in (pre)frail elderly on frailty, functional, and cognitive status: a systematic review. Clin Interv Aging. 2017;12:873-96.

39. Xu J, Li S, Wu Z, Liu W. The vulnerability assessment of family support for the elderly in rural China: An empirical study based on data from Anhui. Popul Res. 2019:43(1):91-101.

40. Li Y, Jiang X, Stone C, Ma Y, Li S. A new physical-cognitive scale for assessment of frailty in Chinese Han elderly. Neurol Res. 2019;41(8):728-33.

41. Chen S, Honda T, Narazaki K, Chen T, Kishimoto H, Haeuchi Y, et al. Physical frailty is associated with longitudinal decline in global cognitive function in non-demented older adults: a prospective study. J Nutr Health Aging. 2018; 22(1):82-8.

42. Kim H, Kim C, Seo SW, Na DL, Kim HJ, Kang M, et al. Association between body mass index and cortical thickness: among elderly cognitively normal men and women. Int Psychogeriatr. 2015;27(1):121-30.

43. Burns JM, Johnson DK, Watts A, Swerdlow RH, Brooks WM. Reduced lean mass in early Alzheimer disease and its association with brain atrophy. Arch Neurol. 2010;67(4):428-33.

44. Joo SH, Yun SH, Kang DW, Hahn CT, Lim HK, Lee CU. Body mass index in mild cognitive impairment according to age, sex, cognitive intervention, and hypertension and risk of progression to Alzheimer's disease. Front Psychiatry. 2018;9:142.

45. Power BD, Helman A, Leon F, Hankey GJ, Yeap BB, Almeida OP, et al. Body adiposity in later life and the incidence of dementia: The health in men study. PLoS One. 2011;6(3):e17902.

46. Howlett DR, Richardson JC, Austin A, Parsons AA, Bate ST, Davies DC, et al. Cognitive correlates of $A \beta$ deposition in male and female mice bearing amyloid precursor protein and presenilin-1 mutant transgenes. Brain Res. 2004;1017(1-2):130-6.

47. An YA, Crewe C, Asterholm IW, Sun K, Chen S, Zhang F, et al. Dysregulation of amyloid precursor protein impairs adipose tissue mitochondrial function and promotes obesity. Nat Metab. 2019;1:1243-57.

48. Xiang X, An R. Body weight status and onset of cognitive impairment among U.S. middle-aged and older adults. Arch Gerontol Geriatr. 2015;60(3): 394-400.

\section{Publisher's Note}

Springer Nature remains neutral with regard to jurisdictional claims in published maps and institutional affiliations.

Ready to submit your research? Choose BMC and benefit from:
- fast, convenient online submission
- thorough peer review by experienced researchers in your field
- rapid publication on acceptance
- support for research data, including large and complex data types
- gold Open Access which fosters wider collaboration and increased citations
- maximum visibility for your research: over 100M website views per year
At BMC, research is always in progress.
Learn more biomedcentral.com/submissions

